\title{
CONTENT ANALYSIS OF GUIDANCE AND PSYCHOLOGY - SPORTS AND RELATED ARTICLES
}

\author{
Engin Baysen ${ }^{1 *}$, Philip Ezekiel Chall Dakwo ${ }^{2,}$ \\ ${ }^{1}$ Institute of Educational Sciences Faculty, Near East University, North Cyprus, Via Mersin 10, Turkey, \\ engin.baysen@neu.edu.tr \\ ${ }^{2}$ Department of Psychological and Guidance Counseling, Institute of Educational Sciences Faculty, Near East \\ University, North Cyprus, Via Mersin 10, Turkey, halldakwo0003@gmail.com \\ Correspondence: engin.baysen@neu.edu.tr ; Tel.: +09 (392) 2236464
}

\begin{abstract}
This research was conducted following a qualitative content analysis of guidance and psychology; sports and related articles between 1937- 2017, with limitations medicine, psychology, health professions, social sciences, biology, engineering, agriculture, computer science etc. Scopus database was sorted to collect the data where 93 documents were got. This article focused guidance and psychology; sports and related areas. Answers were sort for distribution of the articles according by year, source, author, affiliation, country or territory, subject area, subject sample, method, statistics, and sub areas of guidance psychology. There was inconsistency in the incremental level of the articles in guidance psychology but a significance was recorded in 2015 and 2017. The findings revealed until early 2000, most of the writers had one article or never at all. But this changed in the mid 2000 where medicine had the highest and more writers involved as the years passed till 2017. The findings also revealed that the qualitative research was used more than quantitative and mixed methods. The distribution of articles by the sub areas of guidance psychology revealed that human medicine and psychology had the most written articles, while health professions and social sciences followed in writers.
\end{abstract}

Keywords: education, psychology, guidance, sports performance

\section{Introduction}

Psychological guidance counseling addresses the emotional, social, work and physical concerns people may have at different stages, lives, focusing on typical life stresses and more several issues with which people may struggle as individuals and part as families, groups and organizers. It also attends to the needs of students, parents, guardian's professional associations and communities, as well as involves individual planning and guidance, curriculum instruction, system support and provisions of response services. They may promote student's achievement through individual consultation. Brammer and Shostrom (1977) saw counseling as a way of relating and responding to another person so that he is helped to explore himself through understanding, and also finding and using his strengths to be able to cope more effectively with making appropriate actions. Guidance and psychological counseling is expected to address the "emotion........... social, at different stages.

Similarly, sports are physical activities that go beyond competitive sports (Sports and development org). Jaiyeoba and Ademola (2014) see it as including all forms of competitive physical activities or games which, through casual or organized participation. Its aim is to use, maintain or improve physical ability and skills while providing enjoyment to participants and in some cases entertainment for spectators. It is also to maintain and improve physical activity 
and skills while providing enjoyment to participants and in some cases entertainment for spectators. It is generally recognized as a system of activities which are based in physical athleticism or physical dexterity (Wikipedia, 2017). Rush (2017) said that sports recorded the highest participation in the United States in 2010 - 2011. 55\% of high school students participated. It can positively impact children and adults, providing opportunities to get exercises and spend time with peers in healthy environment. Rush (2017) defined sports as that which can make you stronger and healthier and contributing to lower obesity rates. The department of health and human services, acknowledge that sports tend to have lower body mass index than non-sports men Encyclopedia Britannica (2009), views it as enjoyment and entertainment for spectators and a form of physical activity to contribute to physical fitness, mental well-being and social interaction which include, play, recreation, organized, casual or competitive sports and indigenous sports or games (Bucher 1979). The Oxford dictionaries (2010) view sports as any activity involving physical exertion and skills in which an individual or team competes against another or others for entertainment. They are generally understood to include physical activities that go beyond competitive sports which apparently become important in the life of young adults, especially of secondary school age where character, values and beliefs of young people are shaped (Bucher, 1979). These activities and interest provide many positive opportunities for children. However, they can also cause some problems, even though they believe that participation in sports will enhance children's school accomplishments others believe that it gets in the way of their children's achievement, whether they help or distract from achievement depends on the extent of children's involvement and the type of experience they have (Rimm, 2008), but it is generally recognized as a system of activities which are based in physical athleticism or physical dexterity (Wikipedia, 2017). Nonetheless, Rush (2017) asserted the positive impact of sports as children and adults, are provided opportunities to get exercises and spend time with peers in a healthy environment. Viewing the gravity of the deficiencies in the sports sector there is therefore the need for, "A healthy nation is always a wealthy nation", therefore pursuing "Menes Sana In capo Sano" a "healthy mind in a healthy body" for a nation as physical and mental wellbeing are pre requisite of great achievement in man's life (Sylvia, 2008). Rush (2017) viewed sports as that which can make you stronger and healthier and contributing to lower obesity rates. The department of health and human services (2017), acknowledge that athletes tend to have lower body mass index than non - athletes. But generally, sports have served and are serving as a unifying agent and an avenue where there can be gotten a cross cultural share of ideas by different nations or cities. Marriages have said to have been gotten through sports. Friendships have been developed and strengthened through it (Burt, 1998) Socially sports have served and are serving as a unifying agent and an avenue where there can be gotten a cross cultural share of ideas by different nations or cities. Marriages have said to have been gotten through it. Friendships have been developed and strengthened through it. How Guidance and psychological counseling on the other hand addresses the emotional social, work and physical concerns people may have at different stages, lives, focusing on typical life stresses and more several issues with which people may struggle as individuals and part as families, groups and organizers (Banal, 2017). It also attends to the needs of student, parents, guardian's professional associations and communities. It involves individual planning and guidance, curriculum instruction, system support and provisions of response services. They may promote student's achievement through individual consultation (Banal 2017). Brammer and Shostrom (1977) saw counseling as a way of relating and responding to another person so that he is helped to explore himself through understanding, and also find and use his strengths to be able to cope more effectively with making appropriate actions. 
Beautiful as these may be, the question is asked, have the guidance and psychological counselors worked in this direction? Secondary Schools that have a population of two hundred and fifty (250) in the final year may have only 15 of them writing physical education examination while the rest are in English, Mathematics or technical classes Sports which are synonymous to physical exercise are expected to build a healthy mind and a healthy nation. It is also expected to provide skills, athleticism, dexterity, enjoyment and entertainment. Moreover, it now serves as a means to livelihood. Example is drawn from Lionel Messi of Barcelona, Neymar of Paris Saints Germaine, Usain Bolt of Jamaica, Serena Williams of Great Britain, Samuel Etoo of Cameroon, Didier Drogba of Cote de"viore, Kanu Nwankwo and Mikel Obi of Nigeria, Victor Moses of Nigeria, Anthony Joshua Britain, who earned and are earning millions of dollars per week as their pay or salary.

Money have been invested in building facilities in the various Schools and communities, have these things been fully utilized as the students are guided and directed to meet their needs by the counselors? Schools are burnt down, injuries are sustained, equipment are damaged, officials molested, during and after sports meet, have emotions been addressed by counselors? It is on this basis that the researcher is set to assess the efficacy of guidance and psychological techniques in sports performance in secondary schools.

\section{Research Questions}

Beautiful as these may be, the question is asked, have the guidance psychologists and researchers worked in this direction with the students in all educational institutions globally especially considering the rate of article publications on the basis of year, source, author, country, subjects and affiliation? Sports which are synonymous to physical exercise are expected to build a healthy mind and a healthy nation. It is also expected to provide skills, athleticism, dexterity, enjoyment, entertainment and serves as a means to livelihood to many youths and students of various categories in the contemporary of world today. Thus, more research works need to be concentrated on this aspect of sport activity which is holding such a robust sector that have proper people and nations of the world physically, psychologically, economically and socially. It is upon these various aforementioned assertions that this study formulated the research questions as follows:

- What is the distribution of articles publications on yearly basis on Psychological guidance and sport performance?

- What are the distributions of article publications by source, author, country, subject areas and affiliation on psychological guidance and sport performance among students?

- How often is psychological guidance and sport performance mentioned in the overall sampled articles?

- To what extent are these articles practically and theoretically related to psychological guidance and sport performance?

- How related are these articles to the research topic specifically?

- What is the extent of the research methodology? (quantitatively, qualitatively or by mixed method)

\section{Significance of Study}

Economically, money is used to build facilities in various areas thus providing accessibility to the public and indirectly providing a steady sport revenue stream. Sports have always been a primary role of both participants and spectators. Today, sports are often organized, 
mechanized, marketed and administered as business, commercial interest influence virtually every decision in sports (Long \& Sanderson 2001). Wallhead and O'sullivan (2005) asserted that Sports are growing more into business. It is growing into an economic power; it is also attracting commercial interest, which could benefit from that power by influencing its organization (Wallhead \& O sullivan, 2005). Money has been invested in building facilities in the various schools and communities, but have they been fully utilized? Guidance and psychological counseling is expected to address this including the "emotion........... social, at different stages. Schools are burnt down, injuries are sustained, equipment are damaged, officials molested, during and after sports meet, have emotions been addressed? Flaws are committed in sports sector in spite of resources pump into the sector, but leaves much to be desired. Britain, America, Germany, Russia, France and so on have sunk resources into this sector and gets almost equal or equal the input. This therefore made the choice of topic necessary in order to add to knowledge in this area.

\section{Research Methodology}

Content analysis was used for this study. Articles, efficacy of psychological guidance in sports performance and related subjects were selected; medicine, social sciences, pharmacy, psychology, biology, and other relevant areas were sorted and brought together for further analysis.

Content analysis according to Encyclopedia Britannica(2009), says quality research methods is an intellectual way of categorizing qualitative textual data into similar entities, or conceptual categories to identify consistent patterns of relationships between variables or themes. It is the method used to describe systematically written, spoken or visual communications thereby providing qualitative descriptions Long and Sanderson (2001) envisaged content analysis to involve media- print, newspaper, magazines, televisions, videos, and the internet, any medium that can be recorded, reviewed is appropriate. Content analysis, is also used to analyses new materials recorded by the researchers and to classify open ended responses to interview or survey questions. Moreover, descriptive content analysis is serves as a prelude to other types of research, often in domains not previously explored. Content analysis is an end to itself and it is a method used to answer research questions about content. However, it is worth noting that the method also has in conjunction with other research strategies. Content analysis has been used to examine evolution of other academic disciplines. for example, Rush (2017) used 100 key words to classify content of articles published in two clinical psychology and two health psychology journals to characterize the most important theoretical issues facing both disciplines. Banal (2017), saw content analysis as a research method that uses a set of procedures to make valid inferences from texts. Crippen (1980) emphasis on reliability and validity. Rimm (2008), viewed it as a research technique for making replicative and valid references from data to their context. The emphasis is on data which reminds the reader that quantitative content analysis reductionist, with sampling and operational or measurement procedure that reduce communication phenomena to manageable data from which references can be drawn about the phenomena themselves.

\section{Data Collection}

The data was generated from education, psychology, guidance and sports performance, and some other relevant fields where 95 documents for a period of 81 years were obtained from the 
analyzed document by year, source, author, affiliation, country/territory and subject; this is between the years 1937 to 2017 . Each of the articles had methods, sample and statistics.

\section{Data Analysis}

The researcher used Analyzed Search Result buttons to find the distribution regarding the years range, covering the aspect of subjects, methods, samples and statistics. The 95 document result of Psychological guidance in sports performance were counted and analyzed in accordance with the research questions. The data obtained from the articles were analyzed through descriptive, inferential and undefined statistics. The data were put into tables of related subjects, methods, samples and statistics after calculating their frequencies and percentage values.

\subsection{Distribution of Article Publications on Yearly Basis on Psychological Guidance and Sport.}

Table 1. Distribution by Year

\begin{tabular}{llll}
\hline Year & & & F \\
\hline 2017 & & & 12 \\
\hline 2015 & & & \\
\hline 2013 \\
\hline 2012
\end{tabular}

It can clearly be seen from this Table 1 and Graph 1 that 95 documents were analyzed and only 1 article was written in the year 1937, after which 1938 to 1967 there were no articles written. But in 1968, 1997, 1980, 1981, 1987, 1989, 1991, 1994, 1997, 1998, 2002, 2007, one article each was written in the years 1986, 2001, 2002, 2003, 2005, 2009, two articles each were written while in the year 2004, three articles were written. There was increase in the number of articles in the 2008 and 2016 to four each and also increased I the subsequent years, 2006, and 2014 to five articles, this probably was an era of enlightenment to article writing and 
increase in publications. It became evident in the years, 2010 and 2012 when the articles rose to six, articles writing got improvement in 2011 to eight and nine in 2013. In the year 2015, ten articles were written while in the year 2017, twelve articles were written.

Two authors Michele, J. and Theebeem, M. wrote 3 articles each and some three, Luo, Q., Vertonghen, J., and Visscher, C., wrote 2 articles each. Most of the writers 151 of them wrote 1 article each in Scopus Index as discovered by this work in the 81 years of writing of articles. A good look at the graph and the years of publishing, one could see the graph moving up from the year 2014 to 2017 meaning that there will be more articles in years to come. From the inception in 1937, just one article was written and it took till 1968 before another article was written this entails the poor article writing habits at that period. Critically looking at the graph, one will see that it was in 1986, 2001, 2003, 2005 that 2 articles each were written in this area of study. The graph shows the growth pattern of publication rising as the years pass. The years 2006 to 2017 saw a sharp rise of articles in this area, meaning awareness of writing in this field and area of study is becoming more for researchers and academicians. Therefore, it will continue to increase as the years roll pass.

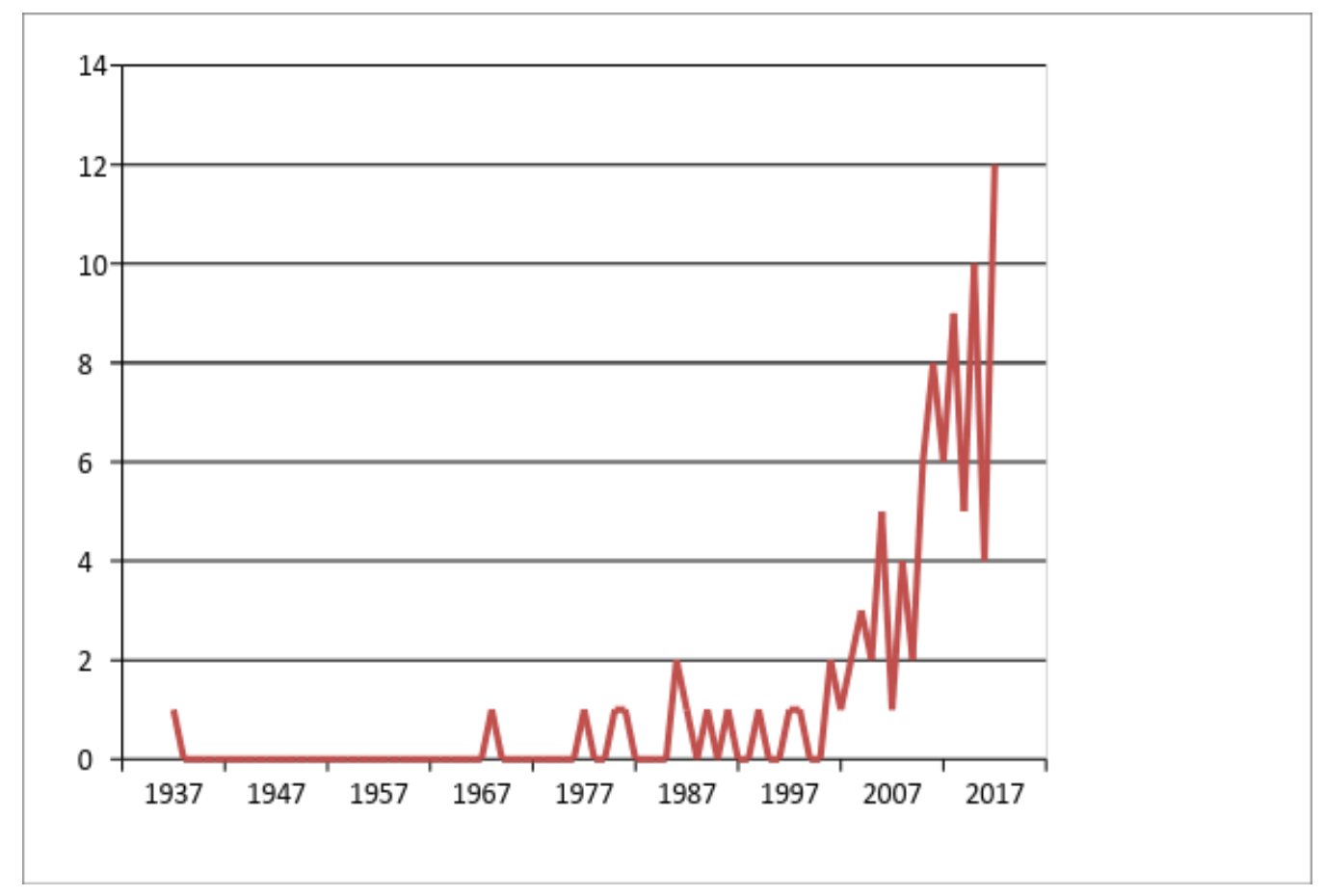

Figure 1. Distribution by Year 


\subsection{Distribution of Article by Source, Author, Country, Subject Areas and Affiliation on Psychological Guidance and Sport Performance}

Distribution of Articles by Source

Table 2. Distribution of Sources

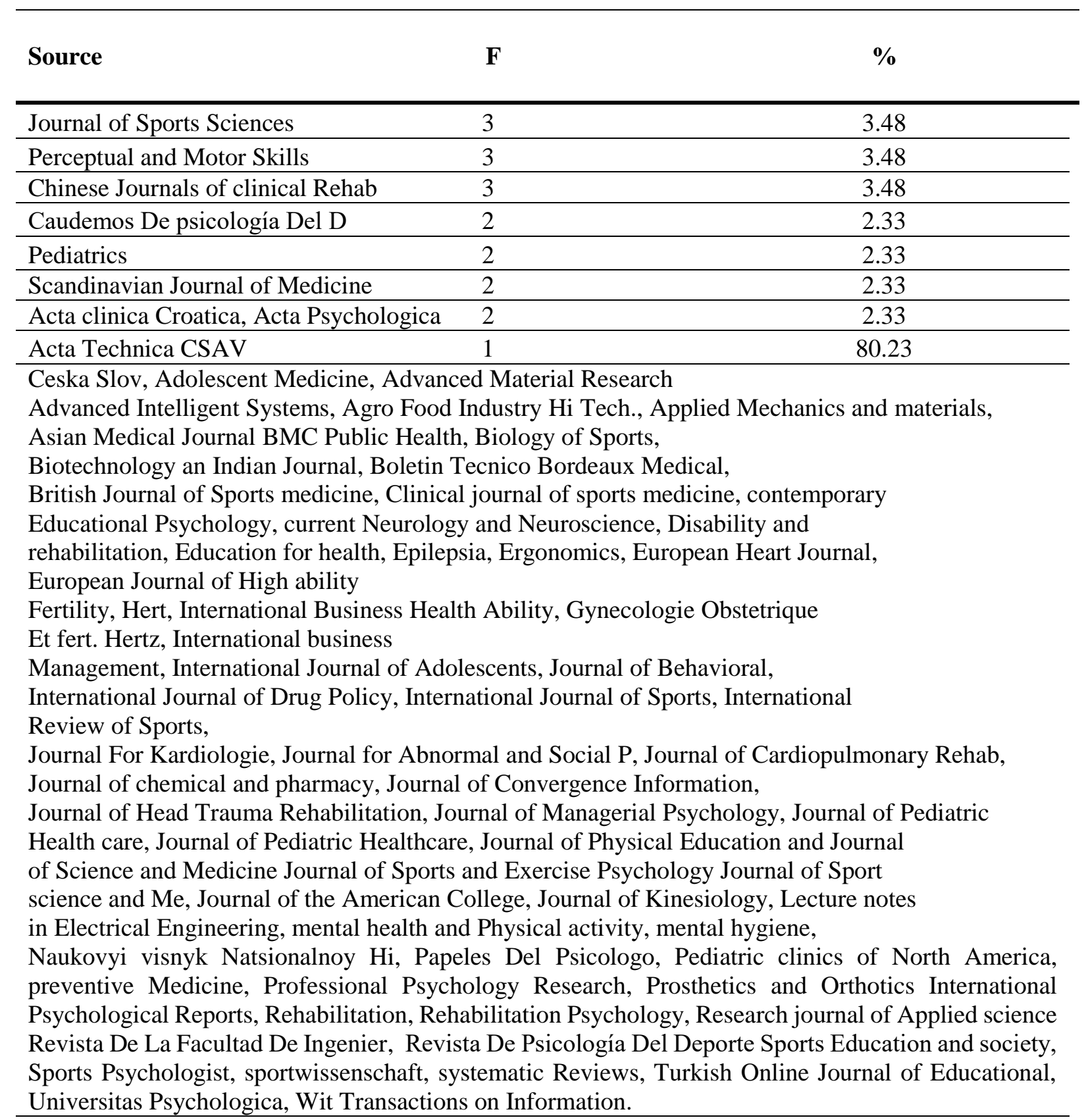

Universitas Psychologica, Wit Transactions on Information.

Grand total

Table 2. Response to sources of articles or publications in 81 years. The study reveals that psychological guidance in sports had been carried out and Egitim Arastirmalari Eurasian, journal of sports sciences, and Perceptual and motor skills had written 3 articles each, while Chinese Journal of Clinical Rehabilitation, Cuadernos De psicología Del Dep, Pediatrics, and Scandinavian each. From these articles, sports journal of sciences and Perceptual and motor skills under sports had 5 articles while medicine had 8 articles, (Chinese journal of clinical 
rehabilitation, Claude Mes De psicologia Del Dep, Pediatrics, Scandinavian journal of medicine,) Although, there might be people who had written articles in the 81 years of research but have not been able to identify them here because of space and more so most of them had an article.

\subsection{Analysis of Article by Authors}

Table 3. Distribution Authors

\begin{tabular}{|c|c|c|}
\hline Source & $\mathbf{F}$ & $\%$ \\
\hline Michele L.J & 3 & 1.8 \\
\hline Theeboom, M. & 3 & 1.8 \\
\hline Luo, Q & 2 & 1.2 \\
\hline Vertonghen, J. & 2 & 1.2 \\
\hline Visscher, C & 2 & 1.2 \\
\hline $\begin{array}{l}\text { Ahmed, MD, Akar, F, Allen, J.B, Aoyagi, } \\
\text { M. W, }\end{array}$ & 1 each & 92.6 \\
\hline Audebert, A, Axelsson K, Backhouse S.H & 151 & \\
\hline \multicolumn{3}{|c|}{$\begin{array}{l}\text { Bailes, J, Ballinger, D.A, Barker.J, Barkoukis V, Barros-Guerrero. A, Barrow } \\
\text { J.C, Berry, J, Biguet. G, Blaine, G.B, Boen F, Bogaerts A, Bovendeerdt. T.J.H, } \\
\text { Brand. R, Breslin.G, Brink M.S, Butki, B.D. Cairmey J, Caliskan, G, Camfield C. } \\
\text { Comfield P, Camire, M, Capovilla.G, Capovilla, Carmen, L.R, Carre, F, Catina.P, } \\
\text { Cavher.E, Chaabene.H, Chamari, Chang, Y.T, Chen.Z Cheour.F, Chirivella } \\
\text { E.C, Clark H.J, Clay, O.J, Clough, P.J, Cohen, A.B, Cox M.K, Crespo, M, Curran, T, } \\
\text { Dawes H, De Knop P, Dede.O, Dolan S.H, Dolenc P, Donnelly.P, Dosil J, } \\
\text { Dosil-Diaz.J, Dreer. L.E, Dudink, A, Duncan S, Echemendia, R.J, Eckerson J.M, } \\
\text { Edwards R.T. }\end{array}$} \\
\hline Grand Total & 163 & 100(rounded) \\
\hline
\end{tabular}

Table 3 accounts for articles published by authors. This reveals that Michelle. J., and Theeboom, M., wrote 3 articles each, while Luo,Q., Vertonghan, J., and Visscher,C., wrote 2 articles each within this period of 81 years. Most of the writers (151) of them had an article each in the index Scopus in these 81 years of study 


\subsection{Analysis by Affiliation}

Table 4. Distribution of Affiliation

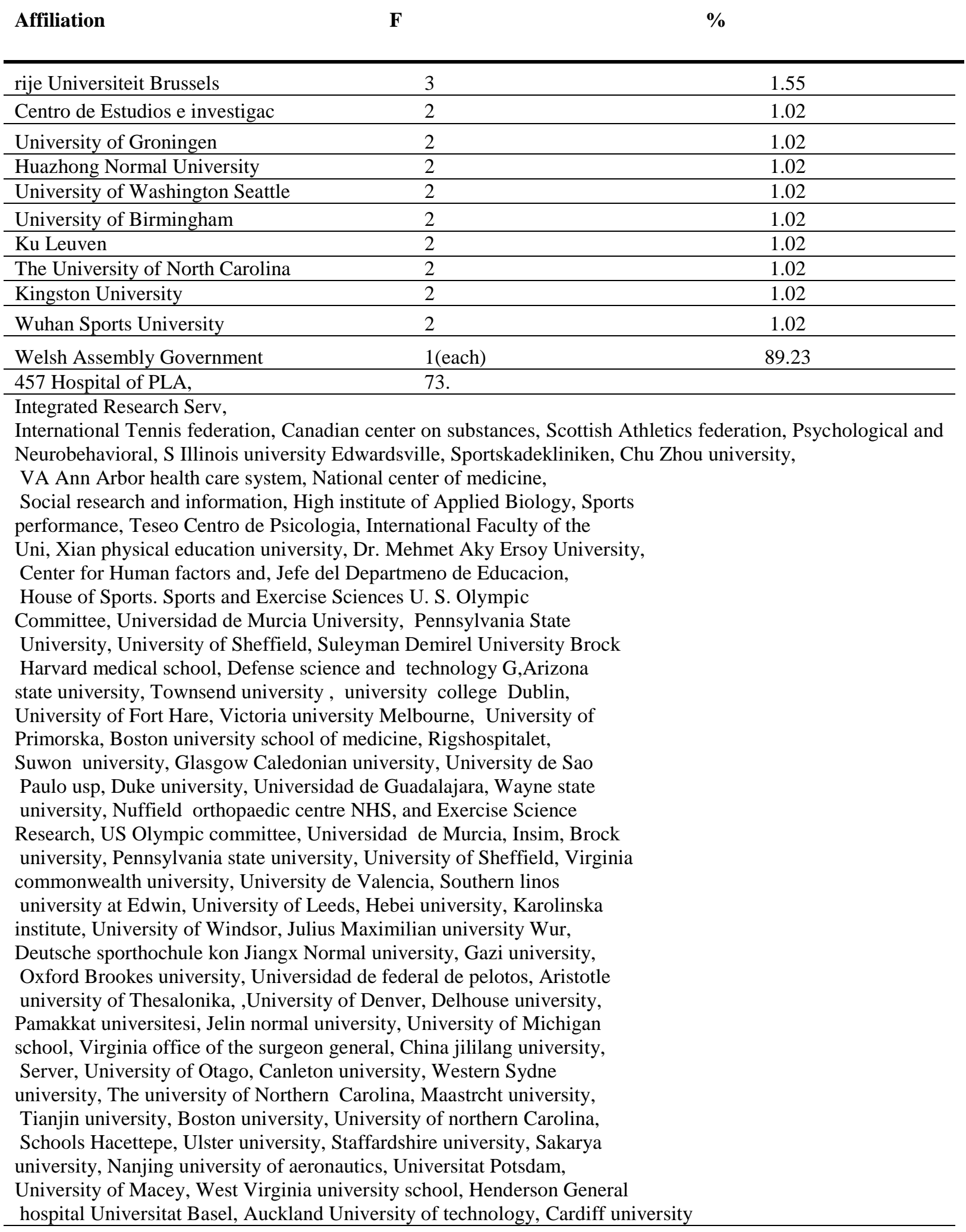


Table 4, responded to the distribution of articles by affiliation and it revealed that Virgi University Brussels published 3 articles and a frequency of $1.55 \%$ while Contro de Estudies, University of Gragningen, Huazhong Normal University, University of Washington, Birmingham, Wuhan sports, had 2 articles each published, which gave a frequency of $1.02 \%$ each giving a total of $9.23 \%$ while most other writers (73) of them had an articles each with a frequency of $89.23 \%$ for all. The research reveals that a total of 195 affiliations were recorded within the period of 81 years.

\subsection{Analysis by Country}

Table 5. Distribution of Country

\begin{tabular}{ll}
\hline Country & F \\
\hline United States & 23 \\
\hline China & 16 \\
\hline United Kingdom & 10 \\
\hline Undefined & 8 \\
\hline Spain & 6 \\
\hline Turkey & 6 \\
\hline Australia & 6 \\
\hline Belgium & 5 \\
\hline Canada & 5 \\
\hline Germany & 5 \\
\hline Netherland & 5 \\
\hline Denmark & 3 \\
\hline Ireland & 3 \\
\hline Italy & 2 \\
\hline Taiwan & 2 \\
\hline Austria, Brazil, Greece & 2 \\
\hline Japan, Mexico, New Zealand & 1 each 17 \\
\hline Oman, Pakistan, Qatar & \\
\hline Russian Federation, Singapore & \\
\hline Slovenia, South Africa, South Korea Sweden, Switzerland, \\
Tunisia & \\
\hline
\end{tabular}

Table 5 reveals the distribution of articles by countries and goes to show us that the United States had 23 articles, while china had 16 and the United Kingdom had 10. There were 8 of the article from unidentified countries. Spain and Turkey had 6 articles each as at the period of the study. Australia, Belgium, Canada and France published 5 articles each while Germany and Netherlands had 3 articles. Denmark, Ireland, Italy, Taiwan published 2 articles each. 17 of the countries including Austria, Brazil, Greece, Japan, Mexico, New Zealand, Oman, Pakistan, Qatar, Russian Federation, Singapore, South Africa, South Korea, Sweden Switzerland and Tunisia had published one article each. 


\subsection{Analysis by Document}

Table 6. Distribution by Document Type

\begin{tabular}{llc}
\hline Document Type & F & \% \\
\hline Article & 66 & 7.5 \\
\hline Review & 10 & 10.5 \\
\hline Conference papers & 8 & 8.4 \\
\hline Book chapter & 4 & 4.2 \\
\hline Book & 3 & 3.2 \\
\hline Conference Review & 1 & 1.1 \\
\hline Article in Press & 1 & 1.1 \\
\hline Note & 1 & 1.1 \\
\hline Grand Total 8 & 95 & 100 (round)
\end{tabular}

Table 6. This accounts for articles type or document type. This is revealed as seen in most of the research done by a review of articles which gave a frequency of 66 articles, and a percentage of 7.5 of the total articles that were researched. A review of reviewed articles were 10 and with a percentage f 10.5 . Conference papers were 8 , with $8.4 \%$ while book chapters were 4 with $4.2 \%$. There were also 3 books reviewed giving 3.2\%. Also, conference review, articles in the press, notes were 1 each, giving $1.1 \%$ of the articles used for this study

\subsection{Analysis by Subject.}

Table 7. Distribution by Document

\begin{tabular}{ll}
\hline $\begin{array}{l}\text { Subject Area (Course) } \\
\text { \% }\end{array}$ & F \\
Course & 8 \\
\hline Medicine & 4 \\
\hline Psychology & 3 \\
\hline Health Professions & 3 \\
\hline Social Sciences & 3 \\
\hline Engineering & 6 \\
\hline Computer sciences & 5 \\
\hline Neurosciences & 3 \\
\hline Business Mgt \& Account & 2 \\
\hline Agric and Biology Science & 2 \\
\hline Earth Planetary Science & 1 each \\
\hline Arts and Humanities, & 8 \\
\hline Biochemistry, Genetics and Microbiology, Decision Sciences, Material & \\
Sciences, Nursing, & \\
\hline Pharmacology Taxocology, Veterinary and Undefined. & \\
\hline
\end{tabular}

Table 7 show the distribution of the subjects that were studied or researched. The table shows that Medicine had 8 articles published, followed by Computer Sciences with 6 articles while Psychology, with 4 articles published within the period of research. Health professions, 
and Social Sciences, Business management, Engineering had 3 articles each. Agricultural science and biology, Earth and Planetary Sciences had 2 articles, but the rest of the courses had 1 article each and also a different article.

\section{Evaluation of Related Articles Theoretically and Practically \\ Relationship of articles to topic}
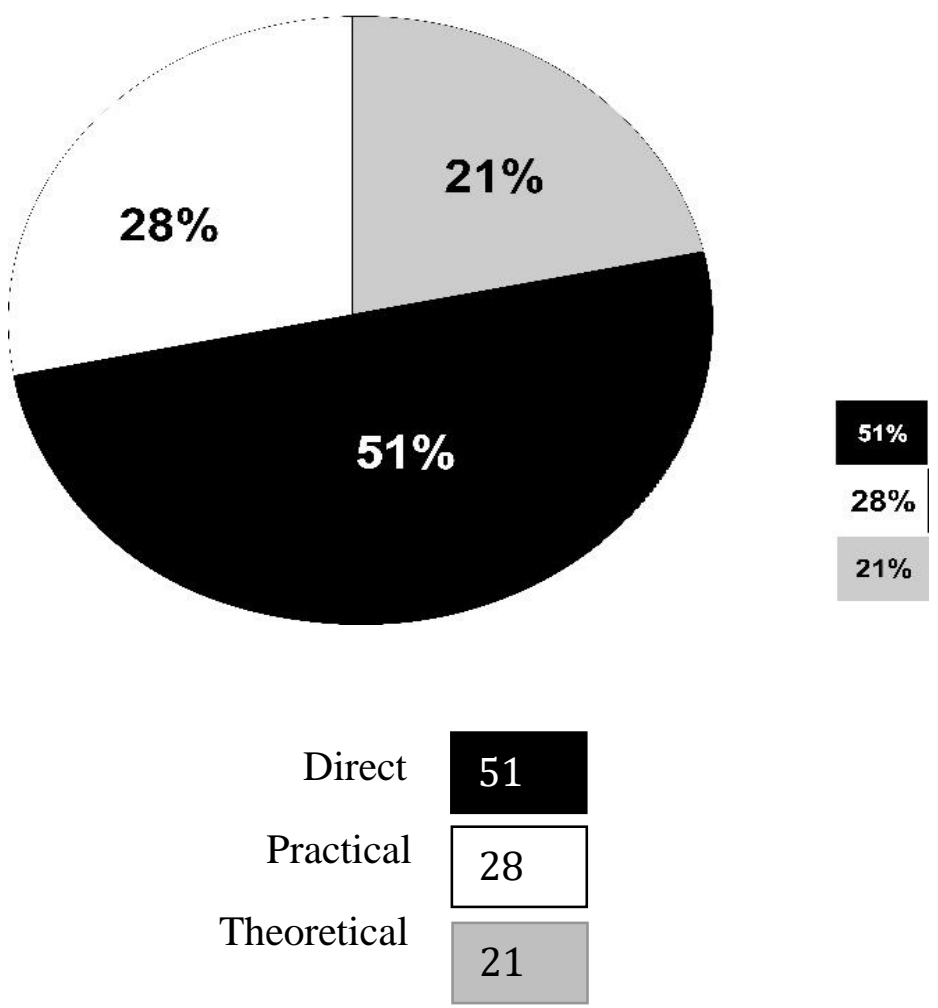

Figure 2. Distribution of Articles Depending on Theory or Practice

The relation of the articles in terms of its theoretical and practical ability to the topic of discussion is seen in the pie chart above (Graph 2). The articles that were directly related to the topic had a frequency of 22 giving $21 \%$ of the total articles that were analyzed. Those articles that were practically related to the topic had a frequency of 54 making $51 \%$, while those that were theoretically related with a frequency of 29 and had $28 \%$ of articles published.

The statistical methods used by the writers in these articles are shown below

Qualitative design........ $77 \quad 81 \%$

Quantitative................17 $18 \%$

Mixed method............1 $1 \%$

\section{Discussion}

This review on content analysis of efficacy of psychological guidance in sports performance in secondary schools had 95 psychological articles and related material were studied between 
1937 and 2017. And additional literature search was used in the sister journals of sports and of psychology in order to come to an agreement of the topic in question from 1960 to 2017. The origin and literature of these journals began this year. The research was conducted through literature review of published articles in the index Scopus database. In other to have a complete overview of all the studied material, $(\mathrm{n}-95), 13,000$ from sports journals and 5,000 that were examined and a careful application revealed a selection criterion which the researcher ended up with 95 materials for the final review. This reveals a high need in the area of study, although there is a ray of hope.

The analyzed search results obtained the articles by year, source, author, affiliation, country and by course in all the 81 years that were researched in content analysis of psychological guidance in sports performance. During the search, other areas that were involved included, Medicine, Biology, Social Sciences, Pharmacy, Health Education, Biochemistry, Computer Science, Agriculture, Microbiology, and similar areas. A close look at the study from 1937, there were no publications again until 1968 where one article was published. The graph continued in that progression until in the year 2004 when the articles increased to 3 and 4 in 2008 and 2016, but in 2006 and 2014 the articles had risen, so the graph isn't normal with the trend of movement. In the year 2015 the articles were 10 while they increased to 12 in 2017 . It is evident that there is a growing increase in publications and therefore shows that there is enlightenment in this area of study, and therefore should expect more articles subsequently. The graph did not give normal curve from the inception but in the subsequent years 2000 to 2017, the curve became visibly normal.

Viewing the distribution of articles by source, for the 81 years' period, Egitim Arastirmalari Eurasian, Journal of Sports Science, Perception and Motor Skills had written 3 articles each, while Chinese journal of Clinical Rehabilitation, Caudemos de Psicologicia del. D., Pediatrics, and Scandinavian Journal of Medicine had 2 articles each. A little look at the journal on sports, one will see that different sources were able to make some good publications between the years 1960 to 2017. Research Quarterly for Exercise published 128 articles, Plos One100, BMC Public Health 93, Archives of Physical Medicine 53, Journal of Sports Science 57, Perceptual and Motor Skill 56, Social Science and Medicine 56, this continued to the list that had 8 publications, un like the others in psychological guidance and sport that have one article each, which clearly shows the need for more articles in the area of sports, going by the number of articles written in these 81 years. Most writers preferred publishing one article this period this is probably because it was at the onset of World War 2 thereby scaring most of the writer to publish. This can be evident in a look at sports articles published from 1960 to 2017 which shows a great difference in the number of articles published, while in 1937 to 201795 articles were published, but from 1960 to 2017 over 13000 articles were published in sports. It is also evident in the psychology journals which showed on increased year in and out. Like in 2015 and 2016 there were 1145 and 1063 articles that were respectively published in these years. Even though the world war had just ended, but the interest of writers was more on sports and psychology than in psychological guidance in sports.

On the distribution of article according to author, the research shows that Michele, L. J and Theeboom, M. wrote 3 articles each while Luo, O., Vertonghan, J., and Visscher, C. wrote 2 articles in this 81 years' period of search. Most authors had one article each and it goes to show that the area has needs for more research and publications. Except for the 2 authors that had 3 articles in the 81 years of research, none again. While a look at articles on sports, one will see that an author has 48 some 39, another 37, 32, 27, 26, 25 to the list person with 8 published articles in the publication, just within the period of 47 years unlike that of psychological 
guidance. Similarly, a cross look at the journal on psychology and sports, authors were able to publish 14, 11,10,9 journals respectively within this same period (1960).

The research also revealed that Virji University Brussels, published, 3 articles with a $1.55 \%$. Contro de Estudies University, University of Gragningen, Birmingham, Kingston, North Carolina, Washington, Ku Levuven, Huazhong Normal University, Wuhan Sports University, published 2 articles each at a cumulated percentage of 9.23, but a frequency of 195 of the affiliates having 89.23 of the total population published only an article each. This shows the inability of the writers to publish articles within the period under research was probably due to the inadequate number of articles which will led to financial lose as this involves a lot of resources. But as seen in the sister journal, on psychology, the University of Toronto, had 109 articles affiliated to them, University of Sydney 87, VA medicine 86, Harvard Medical School 81, University of North Carolina 79, University of Queensland 77, University of California San Francisco 71, University of Washington and Michigan had 70 each so it continued till the last which was the university of Tehran, Alabama, Harvard, Case Western Reserve Nation Taiwan had 18 each. Also, the distribution of articles by country showed that 23 articles were written by the United States followed by China with 16 articles and the United Kingdom 10. Many other nations had 8, 6, 5, 3, and 2 that were published in the years under review. Despite the dare need of Psychological guidance in sports in secondary schools, only South Africa and Tunisia were the only African nations that were able to publish an article each within the years of study. Meaning that Nigeria does not have enough psychological guidance counsellors or no enough writers or researchers and therefore showing a lack in this area and the African continent. It wasn't long that the United States had returned from war, they still took the lead in article writing. With 3256, there were 1907 Undefined articles but the United Kingdom 1136, China, 794, Australia 784, Germany 653, Canada 593, Spain 591, France 502, Russian Federation 445, Brazil 358, It was similar with articles in the journal of psychology and sports. The United States had 2914 publications, United Kingdom 759, Unidentified 742, Canada 540, Australia 539, Netherlands 288, and Germany 282 within the period 1960 to 2017. They were able to continually publish in view of the number of articles received and they used the income generated for more publications.

In the research, there were revelations that topics which were related, were sorted out into frequency of 95 with a percentage of 100. From the studied samples, 95 all came from index Scopus, among which one was unidentified. The medicine had the highest published articles of 8 , while psychology had 4, Health promotions and Social Sciences had 3 articles each. The much written articles from medicine may be attributed to the clinical therapy mental disorders that might have led to much research within the period. But for their counterparts in sports articles, Medical and science in sports wrote 593 articles Teortya. I Praktika Fizicheskoy K., had 396, Research Quarterly for Exercise had 346, journal of strength and condition with 339, Journal of sports Medicine 251, Journals of sports science 243, British Journal of sports Medicine 215, Sports education and society 202 so it continued to the list which was Advances in Environmental Biology having 12 articles. The number of articles as per the subject area in the psychological journal in sports also showed that Medicine had over 5710 publications, Psychology 1151, Social Sciences 987, Health Professions 867, Biochemistry, Genetics, 454, Arts and Humanities, 311, Neurosciences 292, Agriculture and Biological Sciences 149 most of the others had below hundred but the number was greater than that of psychological guidance and sports performance for 81 years. Though it was after the world war, but one can say that writers preferred sports journals and psychology journals rather than psychological guidance in sports, which then shows that there was little or no knowledge of the subject, therefore didn't write on it. 
Further study reveals that most of the documents that were used for the research were review of articles which gave a frequency of 67 articles and a 7.5\% of articles studied, a review of reviewed articles 10 and $10.5 \%$, conference papers were 8 and $8.4 \%$ while book chapter were 4 giving $4.2 \% .3$ books were also reviewed having $3.2 \%$, conference reviews, articles in the press, notes were one each and had $1.1 \%$. Over 6290 documents were reviewed, in the publication of psychology where 843 were from reviewed articles, 145 conference,59 editorials, 48 notes, 43 book chapter, 39 books 36 short survey, 27 letters, 13 articles in the press Erratum 1 of which

Finally, the methods used by these writers were mostly qualitative and had a frequency of 77 that is $82 \%$, quantitative 17 at $15 \%$ while mixed was 1 article making the balance of $1 \%$ the statistics in the research shows that descriptive and inferential were often used, where it has mean, Median, variance, percentage and the inferential had t- test, chi square, multiple regression.

\section{Conclusion}

Psychological guidance is expected to be a guide and assistance to all learners especially in the educational system, where the needed age grade is found for the delivery of tasks, especially as regards sports, therefore to achieve better sports performance, stable emotional, social, physical health concerns of learners, adequate encouragement, motivation, the dare need for psychological guidance is required in all sports programmers especially in secondary schools. A critical view of the 95 documents by this research reveals that there is a great demand for more publications for the awareness of such a barren area of education. A vivid look at the 95 documents analyzed, from the 81 years of documents searched, all the documents area of study was involved, that is, Medicine, Pharmacy, Social Sciences, Microbiology, Health Education and more. Similarly, sister journals in Sports and Psychology was also done. Encouragingly, in all the three different journals, there was an increase in the number of journals daily or yearly only that it was more in the areas of Sports and Psychology than in the area of Psychological guidance in sports. Popular publishers had the most of the publications example, Egitim Arastirmalari Eurasian journal of sports science, Perception and motor skills. But in the sister journals of sports and psychology, there were more publication in about half of the 81 years seen in psychological guidance and sports. There publications were 128 per journal for that period to the list of publications of 8 in 1960 to 2017.

As authors like Michele, $\mathrm{L}$ and Theeboom, $\mathrm{M}$ made the highest publication of 3 articles each for the duration under study in psychological guidance in sports, its sister journals sports and psychology published 48,39,37 journals for the years 1960 to 2017. Also seen in the publisher's number of articles for these years, Virji University Brussels, had 3, while most of the publishers published 2 articles or less, unlike their sports and psychology counterparts in the University of Toronto, 109, Sydney87, VA Medicine 86 and the like. Among the nation that published, United State had the most with 3256, United Kingdom 1136, while china 794 in the year 1960 to 2017 in the sports journals. In Psychology journal, was able to published 1,145 and 1063 articles in 2015 and 2016 respectively. Though medicine took the lead in article publication in the 81 years of search in psychological guidance in sports, with 8 articles, psychology 4, this was nothing compared to the other contemporary journals (Sports and Psychology), Medicine had the lead in the publications also, with 593, Teortya Praktik Fizicheskoy, had 397 articles in 1960 to 2017, in the sports journal, and as Medicine still lead in the Psychology journal production with 5,710 publications, it was followed by psychology with 1,151, while Social Sciences 987 in the year 1960 to 2017. 
Finally, a lot of evidence has proven that most of the writers preferred to write on single journals Sports or Psychology and not on Psychology and Guidance in Sports performance. For these reason the area is still virgin and unexplored and needs exploration.

\section{References}

Bucher, C. A. (1972). Foundations of Physical Education... With 287 Illustrations. CV Mosby Company.

Britannica, E. (2009). Encyclopædia britannica. Chicago: Common Law.

Burt, R. S., Jannotta, J. E., \& Mahoney, J. T. (1998). Personality correlates of structural holes. Social Networks, 20(1), 63-87

Jaiyeoba, A. O., \& Ademola, A. I. (2014). Re-Engineering Tertiary Education (University) For Sustainable Development in Nigeria.

Long, J., \& Sanderson, I. (2001). 12 The social benefits of sport. Sport in the city: The role of sport in economic and social regeneration, 187.

Rimm, S. B. (2008). Why bright kids get poor grades and what you can do about it: A six-step program for parents and teachers. Great Potential Press, Inc.

Wallhead, T., \& O'sullivan, M. (2005). Sport education: Physical education for the new millennium? Physical Education and Sport Pedagogy, 10(2), 181-210.

\section{Biodata of the Corresponding Author}

Associate Professor Doctor Engin BAYSEN was born in Cyprus in 1971. After graduated from elementary and secondary school in Cyprus, he started his university education in 1989 in Ankara Gazi Education Faculty Department of Physics Education and graduated as a Physics and Science teacher. He got his Master and PhD from Ankara Gazi Institude of Sciences Department of Physics Education and Ankara Gazi Institude of Social Sciences Department of Physics Education respectively. He worked as a Science and Physics teacher in numerous primary and secondary schools of Turkey during 1998-2007. After being assigned as an Assistant professor to Kirsehir Ahi Evran University Education Faculty in 2007, and worked for a short time, he started working in Near East University Ataturk Education Faculty in year 2007 and he is still working in Near East University Nicosia Cyprus now. 